\title{
Factors Affecting Net Savings of Thai Households and Students Who Do Statement of Income and Expenses
}

\author{
Aotip Ratniyom ${ }^{1}$, Sutida Plyngam ${ }^{2}$ \\ Faculty of Economics, Srinakharinwirot University, Thailand ${ }^{1,2}$
}

\begin{abstract}
This paper compares the determinants factor affecting net saving between households who do statement of income and expenses in Tumbon Khok Kruat, Amphur Pak Phli, Nakhon Nayok and the students of Srinakharinwirot University by collecting the data from 50 samples of households in Tumbon Khok Kruat, Ampur Pak Phli, Nakhon Nayok and the data from 50 samples of Srinakharinwirot University students who do statement of income and expenses. Overall, the results indicated that the occupational income was the main factors to increase their net saving. However, there was no relationship between their supplementary income and their net saving in a student sample, while both supplementary income and other income had a positive effect on net saving of household in Nakhonnayok. Furthermore, we also divided the household samples in Nakornnayok into two groups, which were aged more than 60 years old and less than 60 years old. We found three types of revenues including the occupational income, other income, and the supplementary income had no effect on net saving in the group of aged more than 60 years old, while the occupational income and other income had a positive effect on their net saving in the group of aged less than 60 years old. Finally, we compared factors affecting between the students who come from outsides Bangkok and students who live in Bangkok. We found three types of revenues positively significantly affected their net saving of students who lived in Bangkok, while the occupational income is the only factor affecting the savings for the students who come from outsides Bangkok.
\end{abstract}

Keywords: Net Saving, Supplementary Income and Occupational Income 